personal observation has such a favourable influence on what young pupils have to do ; in examinations, for example, it is a common experience to find diagrams of plant structure slavishly reproduced from text-books. This brought up the question of training. There was an almost unanimous opinion that university courses in biology are not designed to train teachers for their work, particularly in relation to field studies. Some reform of university courses is essential. Little guidance, too, is forthcoming from the usual type of biology text-book.

As indicated above, the day's proceedings did not do much to help the biology teacher in a grammar school situated in the midst of a thickly built-up area. Certain suggestions were made, but they touched only the fringe of the problem, and it appeared as if the best procedure is to arrange for the pupils to attend short courses at field centres in rural areas. Several speakers commented on the waning of interest in living things among boys and girls in the middle range of grammar schools; they attributed this mainly to the pressure of work in preparing for the General Certificate of Education. No comment, however, was made by teachers on the field studies carried out by young people as a purely voluntary, spare-time activity, particularly during the holidays. Studies of this nature may be fostered by school natural history societies. They bring out certain special educational considerations since they are personal and not directed. They are also the purest source of natural history. R. WEATHERALL

\section{POLISH MATHEMATICAL CONGRESS}

'T HE eighth Congress of Polish Mathematicians was held in Warsaw during September 5-12, and was attended, by invitation, by about forty-two mathematicians from outside Poland. There were two British mathematicians present.

The main sections of the Congress were concerned with mathematical logic ; the theory of probability and its applications to statistics; modern mathematical methods, especially those of functional analysis and topology and their application to the classical theory; and the role of mathematics in physics and technology. In addition to the main conferences, held mostly in the morning, there were many sections at which short papers were read.

It is interesting to recall the salient features of the Polish school of mathematics. Before the Second World War this school had two main centres, in Warsaw and Lwów respectively. The Warsaw school was occupied largely with the theory of sets and with mathematical logic, and it was in these two branches that it had its greatest achievements. We owe to the Polish set theorists, in particular, some very beautiful theorems on the topology of the plane, such as the extension to certain classes of continuous functions of a form of Weierstrass's theorem on the decomposition of an integral function into primary factors, and Rouché's theorem on the zeros of a holomorphic function inside a closed contour. These extensions have thrown new light on the topological character of these theorems on functions of a complex variable. The Polish school of mathematical logic is perhaps even better known, for the contributions of Polish mathematicians stand out in practically every branch of this subject.
The most outstanding contributions of the Lwów school were in the domain of functional analysis, with which the name of Banach is so intimately associated. It was Banach's work which laid the foundation for so much of modern analysis, and with his death, in the summer of 1945, the world lost a great mathematician. Under his guidance the mathematical life in Lwów, in the years before the War, was very free and friendly, with mathematical discussions taking place frequently in cafés. One of Banach's institutions was what became known as the "Scottish Book"-a book of problems contributed by the Lwów mathematicians, and any others who happened to be visiting Lwów. It was kept in a café frequented by mathematicians, after which it became known. The result was a very interesting collection of mathematical problems. It has survived the War, and a new "Scottish Book" has been started at Wroclaw, where the Lwow Institute has been re-established.

Polish mathematicians suffered enormous losses during the War. Some fifty-four lost their lives, very many in almost unbelievable circumstances, a loss which represented a ratio of about one in four. Immediately after the Nazi invasion those of Jewish descent were declared outlaws. This meant that some were shot almost at once, while others managed to survive in hiding until the summer and autumn of 1943 , when they were either shot by the Gestapo or sent to the gas chambers. Saks, Schauder, Auerbach, among very many others, perished in this way. Banach and Mazurkiewicz both died within a few months of liberation. Very many of those who died were young men who had yet to make their full contribution to mathematics, and their loss to Polish mathematics is incalculable. Lives lost cannot be replaced; but every effort has been made during the past eight years to do whatever possible to build up the school again. Generous government grants have enabled the various mathematical institutes to re-establish themselves as research centres. At present they are maintaining three journals of international standing, and several others primarily for circulation in Poland. They are also re-issuing the series of "Mathematical Monographs".

The Congress brought out three things very clearly : first, the remarkable continuity in the Polish school; second, the contributions being made by the younger Polish mathematicians, who have grown up in the years since the War; and third, the desire of all for the better exchange of scientific work. It is true that the work of several of the younger men is already known in Great Britain, but more contact is needed between British and Polish mathematicians. Before the War this was partly achieved as a result of the unfortunate necessity for many Poles to seek posts outside Poland. To-day there are plenty of posts for mathematiciars in Poland, and other and happier ways must be found for securing scientific cooperation. It would, for example, be very valuable if some Polish mathematicians were to come to Britain to lecture and hold seminars. Assurances were given at the Congress that for their part they would be very pleased to do so, for they are anxious to develop scientific contact with British mathe. maticians and would, in particular, welcome suitable papers in their journals.

Polish mathematics has a great tradition, and one peculiarly its own, and it is heartening to know that this famous school is re-establishing itself. 